\title{
A IMPORTÂNCIA DOS MOVIMENTOS SOCIAIS NA LUTA PELOS DIREITOS DAS MULHERES A PARTIR DA INCORPORAÇÃO DO DISCURSO DOS DIREITOS HUMANOS
}

\author{
THE IMPORTANCE OF SOCIAL MOVEMENTS IN THE FIGHT FOR THE \\ WOMEN'S RIGHTS FROM THE INCORPORATION OF SPEECH OF HUMAN \\ RIGHTS
}

\author{
${ }^{1}$ Luciana Correa Souza
}

\section{RESUMO}

O presente artigo tem como objetivo analisar o papel dos movimentos sociais na luta pelos direitos das mulheres. Inicialmente, será analisada a origem histórica do termo gênero e a sua conceituação. Posteriormente, será analisado o papel dos movimentos sociais para o desenvolvimento de instrumentos de proteção internacional de Direitos Humanos. Ao final, será analisado o papel dos movimentos sociais na luta pelos direitos das mulheres no Brasil. A partir desta pesquisa conclui-se pela importância dos movimentos sociais na luta pelos direitos das mulheres no contexto brasileiro na busca pela igualdade de gênero através da incorporação do discurso dos direitos humanos.

Palavras-chave: Gênero; Direito Penal; Movimentos Sociais.

\begin{abstract}
This article aims to analyze the role of social movements in the struggle for women's rights. Initially, the historical origin of the gender term and its concept will be analyzed. Subsequently, the role of social movements for the development of international protection of human rights instruments will be reviewed. Finally, the role of social movements will be analyzed in the fight for women's rights in Brazil. From this study was concluded by the importance of social movements in the fight for women's rights in the Brazilian context in the quest for gender equalit by incorporating the discourse of human rights.
\end{abstract}

Keywords: Gender; Human rights; Social movements.

\footnotetext{
${ }^{1}$ Mestranda pelo Programa de Pós-Graduação em Direito pela Universidade Federal do Pará (UFPA) Belém, Pará, Brasil. Bolsista da Coordenação de Aperfeiçoamento de Pessoal de Nível Superior (CAPES). Email: lucianacorrea_00@hotmail.com
} 


\section{INTRODUÇÃO}

O presente artigo tem como objetivo analisar o papel dos movimentos sociais na luta pelos direitos das mulheres no contexto brasileiro. Esse estudo é dotado de relevância tanto no plano teórico, quanto social, pois, historicamente, a sociedade brasileira desenvolveu-se com base premissas androcêntricas que estigmatizam a mulher, diante disso, se analisará a atuação dos movimentos sociais de mulheres na busca pela igualdade de gênero a partir da incorporação da linguagem dos direitos humanos.

No âmbito dos aspectos metodológicos, inicialmente, será examinado o termo gênero, momento em que será examinada a origem histórica do termo, para posteriormente, conceituá-lo. Posteriormente, serão analisados os instrumentos internacionais de proteção de Direitos Humanos das mulheres, e o papel dos movimentos sociais das mulheres na elaboração. No último tópico, será examinada a atuação dos movimentos sociais na luta pelos direitos das mulheres.

A partir do presente estudo será possível responder ao questionamento que norteia essa pesquisa: Qual a importância da atuação dos movimentos sociais de mulheres na luta igualdade de gênero no Brasil? Ao final, concluir-se-á que os movimentos sociais desempenham papel fundamental na busca pela igualdade de gênero através da incorporação da linguagem de Direitos Humanos no âmbito interno como forma de pressionar o Estado a promover alterações legislativas e políticas públicas adequadas com a normativa internacional.

\section{GÊNERO}

Para conceituar o termo gênero é imperioso realizar uma breve análise acerca de sua origem histórica, visto que, é necessário identificar em qual contexto e em que temática o termo gênero se insere de acordo com período histórico.

\subsection{ORIGEM HISTÓRICA}

O termo gênero, muito embora, ligado ao movimento feminista que se desenvolveu, primordialmente, a partir dos anos 70, tem seu surgimento em raízes históricas bem mais antigas e profundas. 
De acordo com Cobo Bedia (1995, p.2), a gênese do termo gênero remonta ao pensamento de Poulain de la Barre no século XVII. A ideia central do autor era de que a desigualdade entre homens e mulheres não era consequência de uma desigualdade natural, mas sim fruto de desigualdades políticas e sociais que redundaram em teorias que postulavam a inferioridade da mulher em relação ao homem:

\begin{abstract}
El concepto de género, sin embargo, tiene unas raíces históricas más profundas que las de los años setenta. La génesis de esta noción se remonta al siglo XVII con el pensamiento de Poulain de la Barre. Este autor, la filiación cartesiana, publicó tres textos en los años 1673, 1674 y 1675 en los que polemizaba con los partidarios de la inferioridad de las mujeres3. La idea central de Poulain de la Barre es que la desigualdad social entre hombres y mujeres no es con secuencia de la desigualdad natural, sino que, por el contrario, es la propia desigualdad social y política la que produce teorías que postulan la inferioridad de la naturaleza femenina.
\end{abstract}

Com o Iluminismo, o termo gênero se consolidou como uma construção social, pois, a partir do século XVIII, os indivíduos passaram a vislumbrar de forma individual e coletivamente que as desigualdades têm origens históricas e não naturais. Ao longo do período Iluminista, foi intensa a polêmica em relação ao sexo, autores como D'Alembert, Condorcet, Madame de Lambert, Olympe de Gouges, entre outros, defenderam a igualdade entre os sexos, além de refutarem os argumentos contrários que sustentavam desigualdades naturais entre homens e mulheres, e as colocavam em uma condição natural de inferioridade.

Muito embora, Rousseau, inspirado nos ideais iluministas, tenha construído sua teoria impugnando as desigualdades sociais, econômicas e políticas. $\mathrm{O}$ autor defendia que a espécie humana era dividida em dois sexos, e que, portanto, a sociedade deveria ser dividida também em dois espaços: o espaço público destinado aos homens e o ambiente doméstico e privado destinado as mulheres. Em sentido contrário, ainda no período iluminista, Mary Wollstonecraft denunciava o pensamento patriarcal de Rousseau e de outros autores que expunham as mulheres como seres débeis e inferiores em relação aos homens.

O século XIX foi um século ambivalente e de luta para as mulheres e o feminismo, as concepções de Rousseau, pautadas na misoginia romântica do sexo feminino, e de autores como Hegel, Schopenhauer, Nietzsche colocavam as mulheres como inferiores perante os homens.

Os discursos científicos do século XIX serviram de sustentação para a manutenção da ordem androcêntrica, baseados no determinismo biológico e no dualismo entre os sexos, reforçaram a dominação do homem sobre a mulher, revigorando as crenças filosóficas e 
religiosas que destacavam a mulher como um ser inferior. Nesse sentido, Bourdieu (2010, p.

28) afirmava:

\begin{abstract}
A força da ordem masculina se evidencia no fato de que ela dispensa justificação: a visão androcêntrica impõe-se como neutra e não tem necessidade de se enunciar em discursos que visem a legitimá-la. A ordem social funciona como uma imensa máquina simbólica que tende a ratificar a dominação masculina sobre a qual se alicerça: é a divisão social do trabalho, distribuição bastante estrita das atividades atribuídas a cada um dos dois sexos, de seu local, seu momento, seus instrumentos; é a estrutura do espaço, opondo o lugar da assembléia ou de mercado, reservados aos homens, e a casa, reservada às mulheres; ou, no interior desta, entre a parte masculina, com o salão, e a parte feminina, com o estábulo, a água e os vegetais; é a estrutura do tempo, a jornada, o ano agrário, ou o ciclo de vida, com momentos de ruptura, masculinos, e longos períodos de gestação, femininos.
\end{abstract}

Convém destacar a importância pensamento de Simone de Beauvoir que, ainda em 1949, se aproximou do conceito de gênero, precedendo mais de 20 anos dos estudos de gênero realizados nos Estados Unidos a partir dos anos 70. Sendo que muitos desses estudos foram pautados, justamente, nos ensinamentos da autora francesa, que afirmou que:

\begin{abstract}
Ninguém nasce mulher: torna-se mulher. Nenhum destino biológico, psíquico, econômico define a forma que a fêmea humana assume no seio da sociedade; é o conjunto da civilização que elabora esse produto intermediário entre o macho e o castrado, que qualificam de feminino. Somente a mediação de outrem pode constituir um indivíduo como um Outro. (BEAUVOIR, 1980, p. 09)
\end{abstract}

Imperioso, portanto, elucidar o papel do movimento feminista para o desenvolvimento do conceito de gênero, em oposição ao determinismo biológico e a visão androcêntrica que pregavam que as diferenças sociais, políticas e econômica entre os sexos eram tão naturais e hierarquizadas quanto as diferenças biológicas, a partir dos anos 70 .

De acordo com Nicholson (2000, p. 02) o termo gênero tem suas raízes históricas no pensamento ocidental moderno pautado em duas importantes ideias:

Gênero tem suas raízes na junção de duas idéias [sic] importantes do pensamento ocidental moderno: a da base material da identidade e da construção social do caráter humano. $\mathrm{Na}$ época do surgimento da segunda fase do feminismo, final dos anos 60, um legado da primeira idéia [sic] foi a noção, dominante na maioria das sociedades industrializadas, de que a distinção entre masculino/feminino, na maioria dos seus aspectos essenciais, era causada, pelos "fatos da biologia". [...] Por causa dessa assunção implícita no sentindo de fincar na biologia as raízes das diferenças entre mulheres e homens, o conceito de "sexo" coloborou com a idéia da imutabilidade dessas diferenças e com a desesperança de certas tentativas de mudança. As feministas do final dos anos 60 valeram da idéia da constituição social do caráter humano para minar o poder desse conceito. 
Muito embora, o feminismo tenha se oposto ao determinismo biológico, destaca-se a crítica de Nicholson (1999) em relação as feministas do final dos anos 60 e início dos anos 70. Para a autora ainda que parte do movimento feminista tenha tentado se distanciar das concepções do determinismo biológico, as feministas, em sua maioria, "aceitaram a premissa da existência de fenômenos biológicos reais para diferenciar mulheres de homens, usadas de maneira similar em todas as sociedades para gerar uma distinção entre masculino e feminino." ( NICHOLSON, 1999, p.3)

Com base nessas concepções, o conceito de gênero é introduzido não como substituto ao sexo, mas como suplementar a ele. Nesse sentido, aduz Nicholson (1999, p. 03/04):

\begin{abstract}
Assim, o conceito de "gênero" foi introduzido para suplementar o de "sexo", não para susbstitui-lo. Mais do que isso, não só para o "gênero" não era visto como substituto de "sexo" como também "sexo" parecia essencial a elaboração do próprio conceito de "gênero". [...] Rotula essa noção de relacionamento entre corpo, personalidade e comportamento de "fundacionalismo biológico", a fim de indicar suas diferenças e semelhanças em relação ao determinismo biológico.
\end{abstract}

Sintetizando as concepções de Nicholson em relação ao fundacionalismo biológico Louro (2007, p. 208) afirma que:

\begin{abstract}
Linda Nicholson rotula essa posição de "fundacionalismo biológico", na qual "dados da biologia" permanecem como uma espécie de fundamento para o social; assumese, nesse caso, que haveria algumas "constantes da natureza" que seriam responsáveis por certas "constantes sociais". Para ela, essa posição cria obstáculos para uma melhor compreensão das diferenças entre as mulheres, entre os homens e, o que é mais instigante, entre quem pode ser considerado homem ou mulher.
\end{abstract}

Feitas tais considerações em relação a ressalva de Nicholson acerca da oposição do movimento feminista frente ao determinismo biológico, na visão de Coco Bedia (1995, p. 04), a teoria feminista almejava:

El objetivo de la teoría feminista es poner de manifiesto que las tareas asignadas históricamente a las mujeres no tienen su origen en la naturaleza, sino en la sociedad. La idea de la jerarquización de los sexos y de la división sexual del trabajo es fuertemente cuestionada por el feminismo. A partir de esta constatación, los estudios de género se orientan en dos direcciones: en primer lugar, analizan críticamente las construcciones teóricas patriarcales y extraen de la historia las voces silenciadas que defendieron la igualdad entre los sexos y la emancipación de las mujeres; en segundo lugar, la teoría feminista, al aportar una nueva forma de interrogar la realidad, acuña nievas categorías analíticas con el fin de explicar aspectos de la realidad que no habían sido tenidos en cuenta antes de que se desvelase el aspecto social de los géneros. 
Dessa maneira, os estudos de gênero, a partir do feminismo se orientavam em dois sentidos, um em relação a análise das construções teóricas patriarcais e de autores que, ao longo da história, defenderam a igualdade entre os sexos e a emancipação da mulher e em um segundo víeis, a teoria feminista forneceu uma nova maneira de questionar a realidade

Assim sendo, a teoria feminista questionava a própria noção de sexo pautada tão somente em diferenças biológicas que impôs o binômio homem/mulher. O movimento feminista, então, elucida que esse binômio também é fruto de um processo cultural que leva em consideração outros fatores além das questões biológicas.

Cumpre ressaltar a importância do movimento feminista em prol dos direitos humanos das mulheres na perspectiva do sistema interamericano. A partir da metade dos anos 70, em virtude do desenvolvimento da teoria feminista, afirmou-se a necessidade de se dar um tratamento específico para as mulheres no âmbito do Direito Internacional.

Nesse sentido, os movimentos feministas, ao lado dos instrumentos proteção de Direitos Humanos, contribuíram para multiplicar as iniciativas que pugnavam por uma resposta específica às questões de gênero, o que culminou, em 1979, na Convenção sobre a Eliminação de Todas as Formas de Discriminação contra as Mulheres (CEDAW).

Outrossim, Coco Bedia (1995, p. 05) destaca a relevância e as críticas da teoria feminista a partir dos estudos do gênero desenvolvidos nos anos 70:

\begin{abstract}
La introducción de los estudios de género supone una redefinición de todos los grandes temas de las ciencias sociales. El género se torna en una categoría de análisis que recorre todos los ámbitos y niveles de la sociedad. De este modo, la teoría feminista abre un espacio teórico nuevo en la medida en que desvela y cuestiona tanto los mecanismos de poder patriarcales más profundos como los discursos teóricos que pretenden legitimar el dominio patriarcal. La teoría feminista impugna tanto las conceptualizaciones de lo femenino como la escasez de poder de las mujeres en las sociedades patriarcales. El discurso feminista es interdisciplinar porque el dominio masculino opera en todos los ámbitos. Sin embargo, el discurso feminista no sólo está orientado a la crítica de los discursos patriarcales, sino, sobre todo, a la destrucción del sistema de dominación masculino. Por ello, uno de los mayores empeños de la teoría feminista es la construcción de una teoría del poder.
\end{abstract}

Feitas tais considerações acerca do desenvolvimento histórico do termo gênero, no item subsequente serão expostos e analisados os conceitos de gênero apresentados pela doutrina. 


\title{
2.2. CONCEITO DE GÊNERO
}

Conceituar o termo gênero não é simples, pois os diferentes conceitos de gênero se relacionam intimamente com o período e contexto histórico em que esse foi desenvolvido, daí a necessidade de fazer uma prévia digressão histórica da origem do termo.

Antes de discorrer acerca do termo gênero, convém destacar a ressalva de Scott (1989, 05/06) em relação aos historiadores que tentam teorizar gênero. Segundo Scott, tais teorias não fugiram do estigma das ciências sociais, pautando a formulação do gênero em explicações causais universais, o que implica no caráter limitado de tais teorias:

\begin{abstract}
$\mathrm{Na}$ sua maioria, as tentativas das(os) historiadoras(es) de teorizar sobre gênero não fugiram dos quadros tradicionais das ciências sociais: elas(es) utilizaram as formulações antigas que propõem explicações causais universais. Estas teorias tiveram, no melhor dos casos, um caráter limitado porque elas tendem a incluir generalizações redutoras ou simples demais: estas minam não só o sentido da complexidade da causalidade social tal qual proposta pela história como disciplina, mas também o engajamento feminista na elaboração de análises que levam à mudança.
\end{abstract}

Ademais a própria utilização do termo gênero se revela de certa maneira contraditória, em virtude do termo ser utilizado de duas maneiras totalmente distintas. De um lado o conceito de gênero é construído em oposição ao conceito de sexo, enquanto que de outra banda os termos sexo e gênero são dependentes entre si. Assim compreende Nicholson (2000, p.01/02) em relação ao termo gênero:

\footnotetext{
"Gênero" a uma palavra estranha no feminismo. Embora para muitas de nós ela tenha um significado claro e bem conhecido, na verdade ela a usada de duas maneiras diferentes, e até certo ponto contraditórias. De um lado, o "gênero" foi desenvolvido e é sempre usado em oposição apara descrever o que a socialmente construído, em oposição ao que a biologicamente dado. Aqui, "gênero" tipicamente pensado como referência a personalidade e comportamento, não ao corpo; "gênero" e sexo" são portanto compreendidos como distintos. De outro lado, "gênero" tem sido cada vez mais usado como referência a qualquer construção social que tenha a ver com a distinção masculino/feminino, incluindo as construções que separam corpos "femininos" de corpos "masculinos". Esse último uso apareceu quando muitos perceberam que a sociedade forma não só personalidade e o comportamento, mas também as maneiras como o corpo aparece. Mas se o próprio corpo é sempre vista através de uma interpretação social, então o "sexo" não pode ser independente do "gênero"; antes, sexo nesse sentido deve ser algo que possa ser subsumido pelo gênero.
}

Outrossim, cumpre trazer o conceito de gênero levantado por Scott (apud Nicholson, 2000, p. 02). Para a autora gênero nada mais é que uma organização social, gênero é não 
somente fruto de uma diferença natural proveniente do sexo. Dessa maneira, o gênero é o conhecimento que estabelece diferenças corporais entre os indivíduos, vejamos:

Gênero é a organização social da diferença sexual. Mas isso não significa que o gênero reflita ou produza diferenças físicas fixas e naturais entre mulheres e homens; mais propriamente, o gênero é o conhecimento que estabelece significados para diferenças corporais. (...) Não podemos ver as diferenças sexuais a não ser como uma função de nosso conhecimento sobre o corpo, e esse conhecimento não é puro, não pode ser isolado de sua implicação num amplo espectro de contextos discursivos.

Lamas (2015), por seu turno, compreende gênero como um conjunto de normas ditadas pela sociedade e pela cultura sobre comportamento feminino e masculino. Cumpre ressaltar que, de acordo com a autora, a dicotomia masculino-feminino baseada nas variantes culturais, estabelece estereótipos que às vezes são tão rígidos que condicionam os papéis e limitam as potencialidades dos indivíduos ao reprimir comportamentos em função do gênero:

El papel (rol) de género se forma con el conjunto de normas y prescripciones que dictan la sociedad y la cultura sobre el comportamiento femenino o masculino. Aunque hay variantes de acuerdo con la cultura, la clase social, el grupo étnico y hasta al nivel generacional de las personas, se puede sostener una división básica que corresponde a la división sexual del trabajo más primitiva: las mujeres paren a los hijos, y por lo tanto, los cuidan: ergo, lo femenino es lo maternal, lo doméstico, contrapuesto con lo masculino como lo público. La dicotomía masculino-femenino, con sus variantes culturales (del tipo del yang y el yin), establece estereotipos, las más de las veces rígidos, que condicionan los papeles y limitan las potencialidades humanas de las personas al estimular o reprimir los comportamientos en función de su adecuación al género. Lo que el concepto de género ayuda a comprender es que muchas de las cuestiones que pensamos que son atributos "naturales" de los hombres o de las mujeres, en realidad son características construidas socialmente, que no están determinadas por la biología. El trato diferencial que reciben niños y niñas sólo por pertenecer a un sexo, va favoreciendo una serie de características y conductas diferenciadas.

Conforme compreende Coco Bedia (1995, p. 01) o conceito de gênero surge a partir da ideia de que feminino e masculino não são atos naturais ou biológicos, mas sim são construções culturais. Sendo que ao longo da história foram construídas diferenças anatômicas entre os sexos, e essas diferenças foram convertidas em desigualdades sociais e políticas:

El concepto de género es la categoría central de la teoría feminista. La noción de género surge a partir de la idea de que lo <<femenino $>>$ y lo <<masculino $>>$ no son hechos naturales o biológicos, sino construcciones culturales. Como señala Seyla Benhabib, la existencia socio-histórica de los géneros - que ella denomina el sistema género-sexo- es el modo esencial en que la realidad social se organiza, se divide simbólicamente y se vive empíricamente1. Dicho de otra forma, a lo largo de la 
historia todas las sociedades se han construido a partir de las diferencias anatómicas entre los sexos, convirtiendo esa diferencia en desigualdad social y política.

É possível, portanto, compreender gênero - enquanto categoria de análise - como um processo cultural, construído no âmbito social, atribuindo lhes fatores sociais, econômicos, culturais, religiosos e políticos. Não pauta-se, portanto, tão somente em uma determinação imposta pela diferenciação de ordens biológicas, como o sexo.

Por fim, é imperioso distinguir, brevemente, os termos sexo e gênero, enquanto o primeiro refere-se às diferenças biológicas entre homens e mulheres, o segundo diz respeito aos costumes, as práticas e padrões a partir de em um determinado contexto sócio-cultural e momento histórico. Nesse sentido, Piscitelli (2012, p. 439) distingue sexo e gênero nos seguintes termos:

A distinção entre sexo e gênero se tornou uma ferramenta conceitual intensamente utilizada na década de 1970, no âmbito das lutas políticas em favor dos direitos das mulheres. Nessa distinção, o primeiro termo remete à natureza e, de maneira mais específica, à biologia, ao passo que o segundo se liga às construções culturais das características consideradas femininas e masculinas.

Tal diferenciação também é elucidada por Mello (2000, p. 148) que destaca o termo gênero como uma construção social:

\begin{abstract}
O conceito de gênero, para as ciências sociais, não se confunde como conceito de sexo; enquanto este estabelece as diferenças biológicas e anatômicas entre homens e mulheres, aquele se ocupa em designar as diferenças sociais e culturais que definem os papéis sexuais destinados aos homens e às mulheres em cada sociedade. Assim, na definição de gênero cabe a afirmação de Simone de Beauvoir "não se nasce mulher, torna-se". O mesmo pode ser aplicado para o gênero masculino. O gênero, diferentemente do sexo, não é natural, mas sim resultado de uma construção social.
\end{abstract}

Dessa maneira, estabelecidos os contornos conceituais do termo gênero e sua diferenciação em relação ao termo sexo, é possível compreender como as diferenças de gênero são oriundas do modelo androcêntrica da sociedade, que resultou na criação de mecanismos que asseguraram a manutenção da dominação da mulher sobre o homem nas diferentes esferas da sociedade. 


\section{PROTEÇÃO INTERNACIONAL DOS DIREITOS HUMANOS DAS MULHERES}

A concepção contemporânea dos Direitos Humanos, fruto do movimento de internacionalização dos Direitos Humanos, iniciada em um contexto pós Segunda Guerra Mundial, em virtude dos horrores e atrocidades cometidas no período da guerra, em especial, pelo regime nazista, tem como marcos inicial, primeiramente, a Carta das Nações Unidas, de 1945, e a Declaração Universal dos Direitos Humanos, de 1948.

A Carta das Nações Unidas instituiu um sistema global de proteção de Direitos Humanos com a criação da Organização das Nações Unidas (ONU), embora tenha sido um marco no movimento dos Direitos Humanos, não previu um rol de Direitos Humanos, nem exigiu a observância de tais direitos por parte dos Estados. Entretanto, o citado instrumento internacional trouxe como um dos objetivos da ONU, os Direitos Humanos e previsão de criação de um órgão para sua promoção, bem como reconheceu, especificamente, a paz e a segurança internacional como interdependentes na proteção de Direitos Humanos.

Mesmo tratando dos Direitos Humanos, de forma esparsa em seu texto, ressalta-se que a Carta das Nações Unidas foi o primeiro instrumento formal dotado de autoridade de proteção em matéria de direitos humanos. Em 1945, a ONU desempenhava papel significativo na proteção desses direitos, impulsionando o desenvolvimento do movimento de Direitos Humanos.

Ao passo que, a Declaração Universal dos Direitos Humanos, de 1948, introduz a concepção contemporânea dos Direitos Humanos, pautada na indivisibilidade e universalidade desses direitos:

\footnotetext{
Neste contexto, a Declaração de 1948 vem a inovar a gramática dos direitos humanos, ao introduzir a chamada concepção contemporânea de direitos humanos, marcada pela universalidade e indivisibilidade destes direitos. Universalidade porque clama pela extensão universal dos direitos humanos, sob a crença de que a condição de pessoa é o requisito único para a titularidade de direitos, considerando o ser humano como um ser essencialmente moral, dotado de unicidade existencial e dignidade,esta como valor intrínseco à condição humana. Indivisibilidade porque a garantia dos direitos civis e políticos é condição para a observância dos direitos sociais, econômicos e culturais e vice-versa. Quando um deles é violado, os demais também o são. Os direitos humanos compõem, assim, uma unidade indivisível, interdependente e inter-relacionada, capaz de conjugar o catálogo de direitos civis e políticos com o catálogo de direitos sociais, econômicos e culturais. (PIOVESAN, 2012, p. 72)
}

Desse modo, a Declaração de 1948 constitui um marco legal na proteção dos Direitos Humanos, pois, a partir dela começa a se iniciou o desenvolvimento do Direito Internacional 
dos Direitos Humanos, que culminou, posteriormente, na adoção de outros instrumentos de proteção internacional. Nesse sentido, Terezo (2014, p. 30) afirma que:

\begin{abstract}
A Declaração Universal dos Direitos Humanos apresenta-se como um marco legal na fase de internacionalização dos Direitos Humanos, tornando-se um instrumento universal, não apenas por reproduzir direitos que advêm da própria natureza humana, com características de abstração e de universalidade, por referir-se a homens e a mulheres, como fazia a Declaração francesa e inglesa e como constitucionalismo incipiente do Ocidente, mas, assim, determina que incumbe ao Estado colocar à disposição os meios materiais e implementar as condições fáticas que possibilitem o efetivo exercício das liberdades fundamentais, exigindo-se uma postura positiva em prol dos direitos ali consagrados
\end{abstract}

O preâmbulo da Declaração Universal dos Direitos Humanos já elucidava a igualdade de direitos entre homens e mulheres. Tal igualdade veio de forma expressa nos artigos 1 e 2 da Declaração de 1948, as quais destacaram que todos os seres humanos possuem dignidade e direitos iguais:

\footnotetext{
Artigo 1.

Todas os seres humanos nascem livres e iguais em dignidade e direitos. São dotados de razão e consciência e devem agir em relação uns aos outros com espírito de fraternidade.

Artigo 2 .

1. Todo ser humano tem capacidade para gozar os direitos e as liberdades estabelecidos nesta Declaração, sem distinção de qualquer espécie, seja de raça, cor, sexo, idioma, religião, opinião política ou de outra natureza, origem nacional ou social, riqueza, nascimento, ou qualquer outra condição. (ONU, 1948)
}

Contudo, o tratamento despendido as mulheres na Declaração Universal dos Direitos Humanos, foi insuficiente para a sua proteção efetiva, não bastava tão somente assegurar as mulheres o direito a igualdade formal, era necessário garantir a igualdade material, reconhecer o direito a diferença.

Portanto, tornou-se necessário um tratamento diferenciado para as mulheres adequado as suas particularidades e peculiaridades que garantisse a igualdade material entre homens e mulheres, pautada no respeito as diferenças. Dessa maneira, foi imprescindível a adoção de instrumentos específicos destinados a proteção das mulheres. Nesse contexto, os movimentos sociais desempenharam um papel importante na luta pelos direitos das mulheres.

Assim sendo, a proteção internacional das mulheres está, intimamente, ligada as lutas e as demandas levantadas pelos movimentos feministas em suas mais variadas feições. Os 
direitos humanos das mulheres não são fruto de uma história linear, são um processo ainda recente e em constante construção.

Impende destacar que tais direitos ainda apresentam grandes objeções por parte dos Estados que invocam questões culturais, religiosas e a sua própria soberania para não aderir aos instrumentos internacionais de proteção das mulheres.

No que concerne ao espectro de proteção internacional das mulheres, Piovesan (2012, p. 70) destaca que o seu desenvolvimento relaciona-se com as diversas feições e vertentes dos movimentos feministas ao longo da história:

\begin{abstract}
A arquitetura protetiva internacional de proteção dos direitos humanos é capaz de refle!r, ao longo de seu desenvolvimento, as diversas feições e vertentes do movimento feminista. Reivindicações feministas, como o direito à igualdade formal (como pretendia o movimento feminista liberal), a liberdade sexual e reprodutiva (como pleiteava o movimento feminista libertário radical), o fomento da igualdade econômica (bandeirado movimento feminista socialista), a redefinição de papéis sociais (lema do movimento feminista existencialista) e o direito à diversidade sob as perspectivas de raça, etnia, dentre outras (como pretende o movimento feminista crítico e multicultural) foram, cada qual ao seu modo, incorporadas pelos tratados internacionais de proteção dos direitos humanos.
\end{abstract}

Em 1979, foi adotada pela Assembleia Geral das Nações Unidas a Convenção sobre a Eliminação de todas as formas de Discriminação contra a Mulher (CEDAW), a qual somente foi assinada pelo Brasil em março de 1983, com reservas a parte dedicada à família, tendo sido ratificada em 1984 pelo Congresso Nacional. Sendo que, apenas, em 1994 foram retiradas as reservas por parte do Estado brasileiro.

No que tange ao papel desempenhado pelos movimentos sociais de mulheres nos anos 70, Tramontana (2011, p.143) afirma que:

\begin{abstract}
El primero dio inicio en la mitad de los años 70, cuando, gracias alaporte de la teoría feminista del Derecho, se fue afirmando la necesidadde una protección específica de las mujeres en el ámbito del DIDH4.Así, también bajo el impulso de los movimientos sociales de mujeres,al lado de los instrumentos de protección general de los derechos detodo ser humano se multiplicaron iniciativas destinadas a dar unarespuesta particular a la problemática de género, que culminaron conla adopción, en 1979, de la Convención sobre la Eliminación de todaslas Formas de Discriminación contra la Mujer (CEDAW, por sus siglasen inglés)
\end{abstract}

A CEDAW é um dos mais importantes instrumentos de proteção da mulher, entretanto recebeu inúmeras reservas por parte dos Estados signatários, principalmente no que se refere à igualdade entre homens e mulheres no âmbito familiar. Nesse sentido afirma Piovesan (2012, p. 76/77): 


\begin{abstract}
No plano dos direitos humanos, contudo, esta foi a Convenção que mais recebeu reservas por parte dos Estados signatários, especialmente no que tange à igualdade entre homens e mulheres na família. Tais reservas foram justificadas com base em argumentos de ordem religiosa, cultural ou mesmo legal,havendo países (como Bangladesh e Egito) que acusaram o Comitê sobre a Eliminação da Discriminação contra a Mulher de praticar "imperialismo cultural e intolerância religiosa", ao impor-lhes a visão de igualdade entre homens e mulheres, inclusive na família. Isto reforça o quanto a implementação dos direitos humanos das mulheres está condicionada à dicotomia entre os espaços público e privado, que, em muitas sociedades, confina a mulher ao espaço exclusivamente doméstico da casa e da família. Vale dizer, ainda que se constate, crescentemente, a democratização do espaço público, com a participação ativa de mulheres nas mais diversas arenas sociais, resta o desafio de democratização do espaço privado- cabendo ponderar que tal democratização é fundamental para a própria democratização do espaço público. (Grifo nosso)
\end{abstract}

Vê-se, portanto, que muitos Estados Partes não incorporam os tratados e convenções de direitos humanos relativos às mulheres, alegando, inclusive a necessidade de manutenção da sua soberania. Contudo, é necessário resignificar o conceito de soberania, visto que esse sofreu sensíveis modificações nos últimos tempos.

Atualmente, há uma maior interligação jurídica internacional, o que redefine o próprio conceito de soberania. Não se vislumbra mais soberania, como a completa autonomia do Estado para agir de acordo com seus interesses, sem limitações jurídicas de qualquer entidade superior, já que hoje os Estados precisam da ajuda e cooperação internacional de outros Estados para alcançar a sua segurança, o bem-estar econômico de seus cidadãos, entre outras questões. Dessa maneira, a atual significação de soberania, para a maioria dos países significa ser membro, em condições razoáveis de igualdade, nos regimes que compõem o sistema internacional.

Durante os anos 90, foram aprovados dois importantes instrumentos de proteção das mulheres no cenário internacional: Declaração sobre a Eliminação da Violência contra a Mulher, que foi aprovada pela ONU em 1993, e a Convenção Interamericana para Prevenir, Punir e Erradicar a Violência contra a Mulher aprovada pela Organização dos Estados Americanos em 1994, também conhecida como Convenção de Belém do Pará.

Ambos reconheceram que a violência contra mulher, seja no âmbito público ou privado, constitui uma grave violação contra os Direitos Humanos, que limita o exercício de direitos pela mulher. No que tange a Convenção de Belém do Pará, esse foi o primeiro instrumento internacional a reconhecer a violência contra a mulher como um fenômeno generalizado. 


\section{OS MOVIMENTOS SOCIAIS NA LUTA PELOS DIREITOS DAS MULHERES NO ÂMBITO DO DIREITO PENAL BRASILEIRO}

Diante do exposto ao longo do presente artigo, é possível, então questionar se o Direito Penal pode servir como instrumento de luta pela igualdade de gênero a partir das pautas e demandas levantadas pelos movimentos sociais que culminam em alterações legislativas e a criação de novos tipos penais no intuito de tutelar novos bens jurídicos e aumentar o espectro de proteção sobre as mulheres.

Para fazer esse exame é necessário, inicialmente, analisar o papel dos movimentos sociais na luta pela igualdade de gênero através da incorporação da linguagem dos direitos humanos.

\subsection{IMPORTÂNCIA DOS MOVIMENTOS SOCIAIS NA LUTA PELA PELOS DIREITOS HUMANOS DAS MULHERES}

Analisar-se-á a importância dos movimentos sociais na luta pela efetividade dos direitos humanos, bem como se dá a forma de incorporação da linguagem dos direitoshumanos nessa luta e qual a importância dos movimentos sociais em relação à proteção dos direitos humanos das mulheres.

Convém, inicialmente, delimitar no que consistem os movimentos sociais, esses devem ser vistos como sujeitos coletivos capazes de alterar a dinâmica política vigente, através da criação de espaços para a participação popular para além do tradicional ambiente institucional. Assim sendo, os movimentos sociais desempenham um papel fundamental na construção de um novo paradigma político voltada para o fortalecimento da cultura participativa.

Conforme compreende Merry (2006), cada vez mais os movimentos sociais fazem uso do discurso dos Direitos Humanos para mobilizar o direito nacional e internacional em benefício das causas por ele levantadas, e em geral o objetivo do direito internacional e, em particular, dos direitos humanos é proporcionar limites ao poder estatal.

Dessa maneira, os movimentos sociais buscam melhorar as condições dos direitos humanos dos indivíduos e grupos vistos como minorias perante a sociedade, como, por exemplo, dos povos indígenas, com objetivo de promover mudanças nas práticas e políticas 
estatais. Assim sendo, os movimentos contemporâneos de justiça social cada vez mais incorporam estratégias que incluam direitos humanos.

Importante salientar o significado dos direitos humanos e a forma como os direitos humanos são incoporados a luta dos movimentos sociais, pois, os direitos humanos assim como eles são essenciais para a proteção dos direitos dos indivíduos contra os abusos do poder estatal, são também plenamente compativeis com as concepções neoliberais. De acordo com Merry (2006), o significado prático dos direitos humanos é produto de histórias políticas e ideologias locais. Os direitos humanos são, portanto, um conjunto aberto e diversificado de ideias.

Outrossim, ainda de acordo com Merry (2006) os movimentos sociais ao fazerem uso direitos humanos e definirem quais as questões que lhes interessam como violações dos direitos humanos vão além da utilização da linguagem internacional em seus próprios termos. Os movimentos sociais, na verdade, ao incorporarem os direitos humanos constroem com base nas estruturas normativas existentes, acrescentando ideias já disponíveis, ao invés de tão somente substituí-las.

Os movimentos sociais, ao incorporarem os direitos humanos as suas lutas no âmbito interno, acrescentam uma nova dimensão a esses direitos de acordo com as particularidades de cada país, ou seja, eles traduzem uma linguagem global de direitos humanos para termos locais.

Verifica-se que, um dos papéis fundamentais desempenhado pelos movimentos sociais é gerar novas reivindicações em matéria de direitos humanos, a fim de pressionar os governos, por via política, para que reconheçam essas novas demandas e atuem nesse sentido.

Como exemplo, dessas novas demandas trazidas pelos movimentos sociais em relação os direitos das mulheres no contexto brasileiro: a Lei Maria da Penha e a Lei do Feminicídio. Tais alterações legislativas no âmbito penal foram fruto de articulações e da pressão exercida pelos movimentos sociais. Embora, o Direito Penal constitua um importante aliado na luta dos movimentos sociais de mulheres, - e ao mesmo tempo palco de luta contra a desigualdade de gênero - a criação de novos tipos penais e alterações na legislação penal com escopo de ampliar o espectro de proteção das mulheres, por si só, não tem o condão de promover a efetiva proteção das mulheres contra a violência e as diversas formas de discriminação.

Nesse contexto, é essencial a atuação dos movimentos sociais, que hoje se encontram articulados com os vários seguimentos da sociedade e tem legitimidade e força política para 
exercer influência nas diferentes esferas de poder. Dessa maneira, os movimentos sociais devem ampliar o seu âmbito de luta, a fim de pressionarem os governos a tomarem medidas efetivas contra a desigualdade de gênero.

É necessário que o poder público atue na prevenção da violência contra a mulher, como por meio da educação, por exemplo, através da inserção das temáticas de gênero nas escolas a fim de educar crianças e adolescentes a respeitarem as diferenças. Bem como é imperiosa a criação de políticas públicas de acolhimento às vítimas, com a disponibilização de mecanismos concretos que permitam a mulher sair do contexto de violência, a melhor estruturação das delegacias e das varas de violência doméstica, com funcionários capacitados para atender as demandas e as necessidades das mulheres em situação de violência.

Diante do exposto, resta cristalina a importância da atuação dos movimentos sociais na luta por direitos humanos. Os movimentos sociais de mulheres, em especial no contexto brasileiro, foram responsáveis por mudanças significativas no cenário político e social, através da disseminação do discurso dos Direitos Humanos, os utilizando como instrumento de luta frente ao arbítrio estatal, sendo capazes de modificar políticas públicas e pressionar o poder legislativo por mudanças na normativa interna a fim de promover os direitos humanos, em especial, das minorias estigmatizadas por questões históricas e culturais, tais como as mulheres.

\section{CONCLUSÃO}

Essa pesquisa teve como objetivo analisar o papel dos movimentos sociais na luta pelos direitos das mulheres. A fim de atingir o objetivo ora proposto, examinei, inicialmente, as origens históricas do termo gênero, além do desenvolvimento da teoria feminista que em muito contribuiu para a superação do determinismo biológico, e o conceito do termo gênero. Foi analisado também o papel dos movimentos sociais na criação dos instrumentos internacionais de proteção da mulher. E, ao final, examinei os movimentos sociais de mulheres na luta pela igualdade de gênero no Brasil a partir da incorporação da linguagem dos Direitos Humanos.

Ao final da pesquisa, verifica-se que os movimentos sociais de mulheres, através da mobilização política e articulação com outros movimentos sociais e atores chaves no cenário político brasileiro, constituem importantes atores sociais no campo da democracia participativa no Brasil. A partir da incorporação da linguagem dos Direitos Humanos na luta 
pela igualdade de gênero no Brasil, os movimentos sociais utilizam-se desse discurso para reivindicar alterações legislativas e políticas públicas mais adequadas com a normativa internacional.

Concluindo-se que é necessário que o poder público atue no sentido de eliminar todas as práticas e condutas que criam e reproduzem o discurso androcêntrico de inferioridade das mulheres. Nesse sentido, torna-se essencial a atuação dos movimentos sociais de mulheres que, em razão de estarem articulados com diferentes seguimentos da sociedade e outros movimentos socais, tem legitimidade e força política para pressionarem os governos a tomarem medidas efetivas contra a desigualdade de gênero.

\section{REFERÊECIAS}

BEAUVOIR, Simone de. O segundo sexo. 2. A experiência vivida. $3^{\circ}$ ed. Rio de Janeiro: Diffel, 1980.

BOURDIEU, Pierre. A dominação masculina. Traduzido por Maria Helena Kühner. $7^{\mathrm{a}}$ ed.. Rio de Janeiro: Bertrand Brasil.

COBO BEDIA, Rosa. "Género" In AMORÓS, Celia. 10 palabras clave sobre Mujer. Navarra, Verbo Divina, 1995, p. 55-83.

INSTITUTO INTERAMERICANO DE DERECHOS HUMANOS. Revista IIDH, n. 53, XX aniversario del Programa Derechos Humanos de las Mujeres, ene./jun. 2011.

LAMAS, Marta. El género és el cultura. Disponível em: http://www.oei.es/euroamericano/ponencias_derechos_genero.php.. Acesso em 17 jul. 2015.

LARRAURI, Elena. Genero e Derecho Penal. Disponível em: http://www.iidh.ed.cr /comunidades/derechosmujer/docs/dm_interinteres/ponencia\%20elena\%20larrauri.pdf.Acesso em 17 jul. 2015.

LOURO, Guacira Lopes. "Epistemologia feminista e teorização social desafios, subversões e alianças". In: ADELMAN, Miriam; SILVESTRIN, Celsi Brönstrup. (Orgs). Coletânea Gênero Plural. Curitiba: Editora UFPR, 2002. p. 11-22.

MELLO, Marília Montenegro Pessoa de. Da Mulher Honesta a Lei com nome de Mulher: $O$ Lugar do Feminismo na Legislação Penal Brasileira. Disponível em http://www.periodicos.ufgd.edu.br/index.php/videre/article/viewFile/885/pdf_27. Acesso em 18 jul. 2015 
MERRY, Sally Engle. "Derechos Humanos, género y nuevos movimentos sociales: debates contemporâneos en antropologia jurídica" In CHENAUT, Victoria; GÓMEZ, Magdalena; ORTIZ, Héctor; SIERRA, María Teresa (Coords.) Justicia y Diversidade en América Latina. Pueblos indígenas ante la globalización. México/Ecuador, Ciesas/Flacso, La Casa Chata, 2011, p. 261-289.

NICHOLSON, Linda. "Interpretando o gênero". Revista Estudos Feministas, v. 8, n. 2, p. 941, 2000.

PIOVESAN, Flávia. A Proteção Internacional dos Direitos Humanos da Mulheres. Revista da Emerj, Rio de Janeiro, v. 15, n. 57, p.70-89, jan. 2012. Disponível em: http: //www.emerj.tjrj.jus.br/revistaemerj_online/edicoes/revista57/revista57_70.pdf. Acesso em: 16 jul. 2015.

PISCITELLI, Adriana. Sexo e Gênero. In SOUZA LIMA, Antonio Carlos (Coord.). Antropologia \& Direito: temas antropológicos para estudos jurídicos. Brasília/Rio de Janeiro, Contra Capa/ LACED/ABA, 2012, p. 439-447.

SCOTT, J. Gênero: uma categoria útil de análise histórica. Revista educação \& realidade. v.15, n.02, jul./dez.1995. Traduzido da versão em Francês, com consulta ao original em inglês. p. 71-99

ZAMBRANO, Elizabeth \& HEILBORN, Maria Luiza. "Identidade de gênero" In SOUZA LIMA, Antonio Carlos (Coord.). Antropologia \& Direito: temas antropológicos para estudos jurídicos. Brasília/Rio de Janeiro, Contra Capa/ LACED/ABA, 2012, p. 412-419.

ZÚÑ̃IGA, Yanira. "Ciudadanía y género. Representaciones y conceptualizaciones em el pensamento moderno y contemporâneo" In CULLETON, Alfredo; MAUÉS, Antonio; TOSI, Giuseppe; ALENCAR, Maria Luiza; WEYL, Paulo (Orgs.). Direitos humanos e integração latino-americana. Porto Alegre: Entrementes, 2011, p. 277- 296. 